\title{
The Synthesis and Chemistry of Certain Anthelmintic Benzimidazoles
}

\author{
L.B. Townsend and D.S. Wise
}

A basis for interest in the benzimidazole ring system as a nucleus from which to develop potential chemotherapeutic agents was established in the 1950s when it was found that 5,6-dimethyl-1( $\alpha$-D-ribofuranosyl)benzimidazole (I) was an integral part of the<smiles>Cc1cc2ncn(C[C@H]3O[C@H](CO)[C@@H](O)[C@H]3O)c2cc1C</smiles>

I

structure of vitamin $B_{12}$. As a result of these interests and extensive studies, one health related areno that has benefited greatly has been the treatrnent of parasitic diseases. The discovery of thiabendazole in 1961 further spurred chemists around the world to design and synthesize several thousand benzimidazoles for screening for anthelmiritic activity but less than twenty of them have reached commercial use. Much of this work has been done by pharmaceutical companies and is only reported in the patent literature. In this paper, Leroy Townsend and Dean Wise review the development of some of the synthetic methods that have been critical to the preparation of the benzimidazoles of anthelmintic importance. Only o few molecules that demonstrate the processes are discussed here, but numerous reviews of the synthesis and chemistry of other benzimidazoles ore available ${ }^{l-3}$.

\section{Box I. Tautomerism and isomerism}

The systematic numbering of the benzimidazole ring system is shown in structure I. Although benzimidazole is depicted in I as possessing the proton at $N_{1}$, there actually exists a rapid exchange between the $-\mathrm{NH}$ - and $=\mathrm{N}$ - nitrogen atoms, and two tautomers, I and II, may be drawn for the benzimidazole mol-<smiles>C#CC#C</smiles>

I<smiles>c1ccc2[nH]cnc2c1</smiles>

II ecule. Tautomerism occurs through either an intermolecular process involving two or more benzimidazole molecules or through interactions with a protic solvent such as water. It renders the 5- and 6-positions, and any group at that position in the ring system, chemically equivalent. In $\mathrm{N}$-substituted benzimidazoles, tautomerism is no longer possible and two distinct non-equivalent molecules or isomers may be isolated and characterized. For example, the two dimethylated benzimidazoles shown are an isomeric pair of non-equivalent molecules, while the mono-methylated molecules are tautomers and equivalent.<smiles>Cc1ccc2nc[nH]c2c1</smiles>

Benzimidazole, as the name implies, is a bicyclic ring system in which benzene has been fused to the 4- and 5-position of the heterocycle (imidazole; Box I). Benzimidazole compounds in general, and benzimidazole carbamates in particular, are crystalline materials, with fairly high melting points and are relatively insoluble in water. Compounds that are unsubstituted on either of the imidazole nitrogen atoms possess both acidic and basic characteristics.

Modifications of the benzimidazole ring system that have been made during the search for anthelmintic activity are summarized in Box 2. Combinations of the modifications at positions 2- and 5- of the moleculc has provided the most active drugs. The synthetic pathways to the various benzimidazoles usually proceeds through two steps, first the construction of a benzene ring containing the desired substituents and a 1,2-diamine grouping, followed by the ring closure of the 1,2-diaminobenzene (o-phenylenediamine) derivative to construct the imidazole ring. In many cases, this ring closure is the<smiles>[R]c1ccc(N)c(N)c1</smiles>

o- phenylenediamine

$\mathrm{R}, \mathrm{R}^{\mathrm{t}}=$ ring substitution

final step in the synthesis of the desired benzimidazole. However, in other instances this ring closure is followed by extensive derivatization of the ring system or of the existing exocyclic substituents (Bo 3 ).

The discovery ${ }^{4}$ in 1961 that 2-(4'-thiazolyl)benzimidazole (thiabendazole) possessed a very potent broad spectrum of activity against gastrointestinal parasites was the breakthrough that opened up a new era in the treatmcnt of parasitic diseases. In the initial studies, a group of researchers at Merck prepared thiabendazole by a condensation of $\boldsymbol{o}$-phenylenediamine with thiazole-4-carboxamide in the presence of the dehydrating agent, polyphosphoric acid. This reaction was found to be quite<smiles>Nc1ccccc1N</smiles><smiles>NC(=O)c1cscn1</smiles>

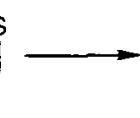<smiles>c1ccc2[nH]c(-c3cscn3)nc2c1</smiles>

Thiabendazole

general in nature and several hundred derivatives, including the 2-(2'-furyl)-,2-phenyl-,2-(2'-naphthyl)-, and 2-(5'-thiazoyl)congeners, were also prepared to determine the best candidate for commercial development. Both the 2-phenyl- derivative and thiabendazole were very active drugs, and were

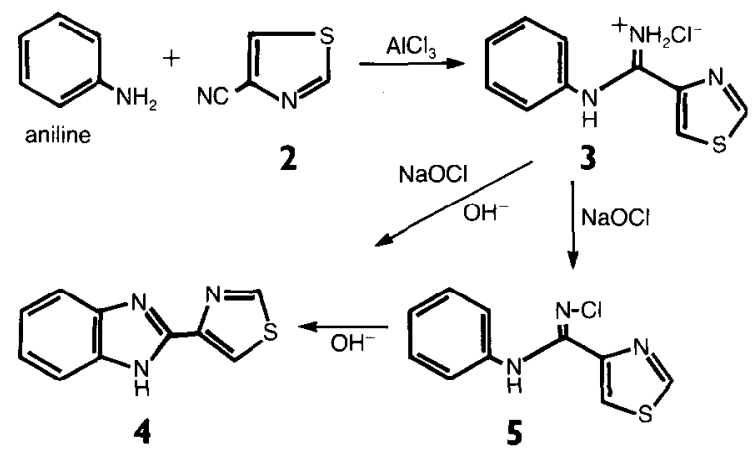




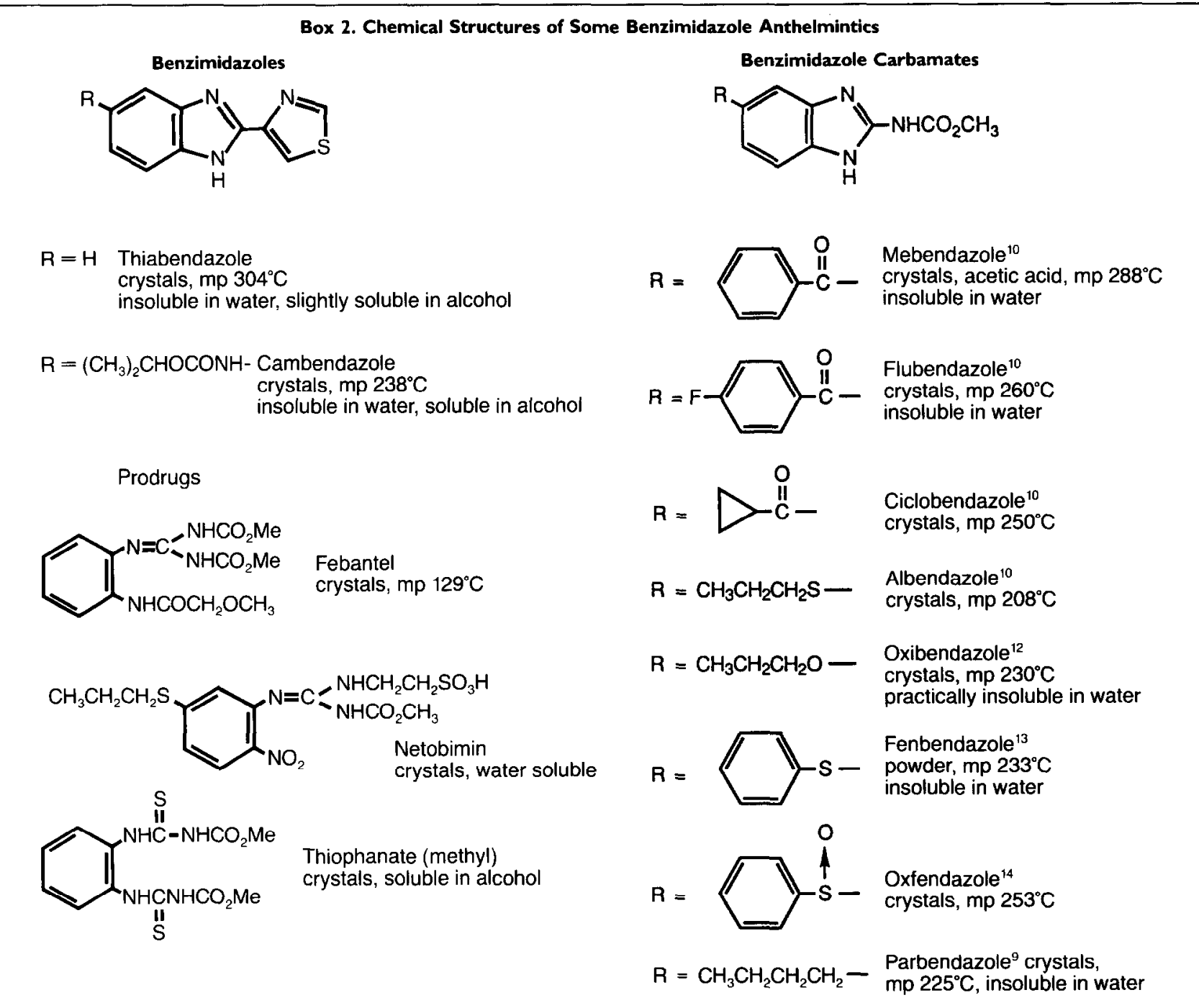

studied further. A new, efficient procedure for the conversion of $\mathrm{N}$-arylamidines with hypochlorite and a base to form benzimidazoles was devised by the Merck group ${ }^{5}$, and this discovery made it economically practical to market the 2-phenyl derivative and thiabendazole. In this procedure it is unnecessary to prepare the o-phenylenediamine compound because aniline is used as a starting material. Thus, to prepare thiabendazole (4), aniline is reacted with 4-cyanothiazole (2) in the presence of aluminium trichloride (a Lewis acid), to give the intermediate $\mathrm{N}$-arylamidine hydrochloride (3). The critical oxidative cyclization to give (4) is then carried out by treating (3) with sodium hypochlorite in the presence of a base. The latter reaction has been accomplished commercially in one step, but it may also be performed stepwise through the intermediate $(\mathbf{5})$.

It was later found that both thiabendazole and 2-phenylbenz imidazole suffer from an enzymatic hydroxylation at the 5 -position to give (6), which inactivates the drug and therefore<smiles>c1ccc2[nH]c(-c3cscn3)nc2c1</smiles>

thiabendazole

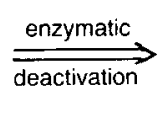<smiles>Oc1ccc2[nH]c(-c3cscn3)nc2c1</smiles>

limits its effectiveness. To overcome this problem, investigators began to prepare second generation benzimidazoles with structural modifications that might prevent metabolic inactivation. These studies led to an abundance of potential anthelmintic benzimidazoles, and many methods of preparation.
Since hydroxylation was occurring at the 5-position, analogs of thiabendazole with different groups at this position were developed. As a potential candidate, 5-aminothiabendazole (9) was prepared by a condensation of 4-nitrophenylenediamine (7) with (2) to furnish 5-nitrothiabendazole (8). The nitro group of compound (8) was then reduced to furnish 5aminothiabendazole (9). Compound (9) was nearly (80\%) as active as the parent thiabendazole. Acylation of the 5-amino

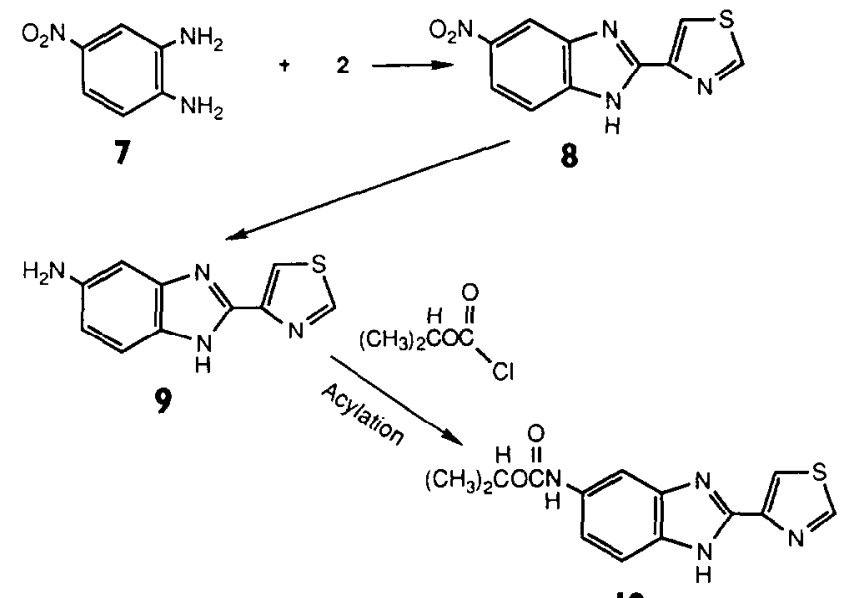

I0 cambendazole

functional portion of (9) with isopropyl chloroformate produced the 5-isoproxycarbonylamino derivative (10), which was marketed under the name cambendazole ${ }^{6}$. Later, 
<smiles>CC(C)COc1nc(-c2nc3ccccc3[nH]2)cs1</smiles><smiles></smiles>

10

cambendazole was prepared directly from thiabendazole by an electrophilic substitution of a nitrene or nitrene-like intermediate derived from isopropyl azidoformate, initiated by heat or UV light'. Another unique synthesis of cambendazole involves a reduction of the 3-(4-thiazolyl)benzotriazine l-oxide (I I) $)^{8}$.

Through a systematic study involving a modification of the thiazole ring at the 2-position of thiabendazole, workers at Smith Kline and French found that the thiocarbonate compound ( $\mathbf{1 2 a}$ ) possessed anthelmintic activity ${ }^{9}$. This led to the preparation of 2-acylarninobenzimidazoles (12b), 2-benz-

$$
\begin{aligned}
& \text { 12a } x=S, R=O C_{2} H_{5} \\
& 12 b \quad x=O, R=a k y l \\
& 12 \text { c } x=O, R=\text { alkoxy } \\
& 12 \text { d } x=O, R=\text { akylamino }
\end{aligned}
$$

imidazolylcarbamates (I 2:c) and 2-benzimidazolylureas (I2d). All of these compounds possessed anthelmintic activity, however, the 2-methylcarbannate derivative stood out as the most

effective. Several compounds were prepared that possessed this group at the 2-position. One of these compounds, prepared by the reaction of 4-butyl-o-phenylenediamine (13) with carbomethoxycyanamide (14) in boiling propanol, was methyl 5-butyl-2-benzimidazolylcarbamate (15; parbendazole).

Following the introduction of this compound, additional drugs were produced by several pharmaceutical companies. Janssen Pharmaceutica produced mebendazole, flubendazole, and ciclobendazole ${ }^{10}$ among others; Smith Kline and French discovered albendazole ${ }^{1}$, oxibendazole ${ }^{12}$, and fenbendazole $^{13}$; and Syntex developed oxfendazole ${ }^{14}$. To prepare these benzimidazoles, several new ring closing reagents were<smiles>CCc1ccc(N)c(N)c1</smiles>
13
14
15 parbendazole

employed or invented and these 2-methoxycarbamate synthons are shown in Table 1.

To prepare mebendazole, flubendazole, ciclobendazole, and a variety of benzimidazoles containing a group attached to the 5 -position of the benzimidazole by a carbonyl $(\mathrm{C}=\mathrm{O})$ linkage, a general reaction scheme was developed by researchers at Janssen (see Box 3 ). In this synthetic sequence, the initial step is to append to ring $A$, the group which becomes the 5-carbonyl linked substituent. This is accomplished using a

Box 3. Examples of Benzimidazole Modifications Undertaken to Effect Anthelmintic Activity<smiles>[2H]C(=O)c1ccc2[nH]cnc2c1</smiles>

$\mathrm{R}=$ aromatic, $\mathrm{OR}^{\prime}, \mathrm{NHR}^{\prime}$<smiles>CCCNc1ccc2[nH]cnc2c1</smiles>
$R=R^{\prime} O C, R^{\prime \prime C}$, alkyl, aromatic ring<smiles>C=C=C</smiles>
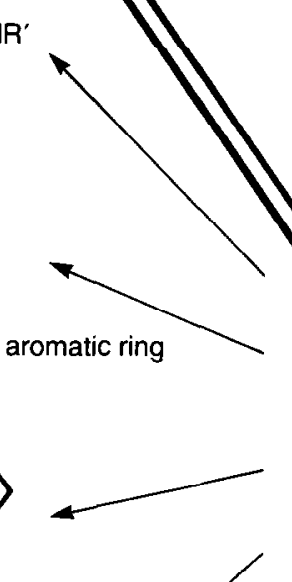

$R=$ alkyl, aromatic ring<smiles>[R]=[AlH]c1ccc2[nH]cnc2c1</smiles>

$\mathrm{R}=$ alkyl, aromatic ring
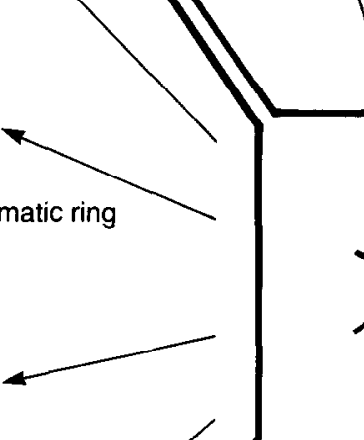

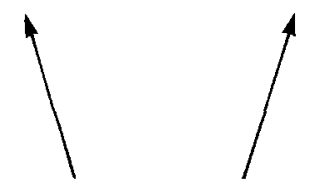<smiles>Cc1cn2ccccc2n1</smiles>
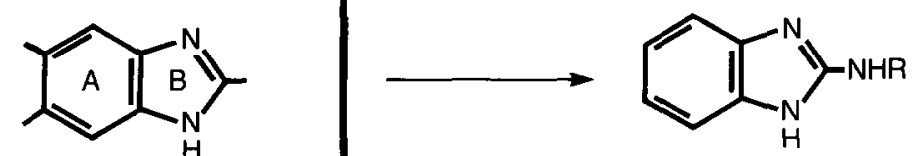

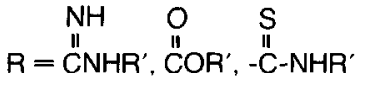
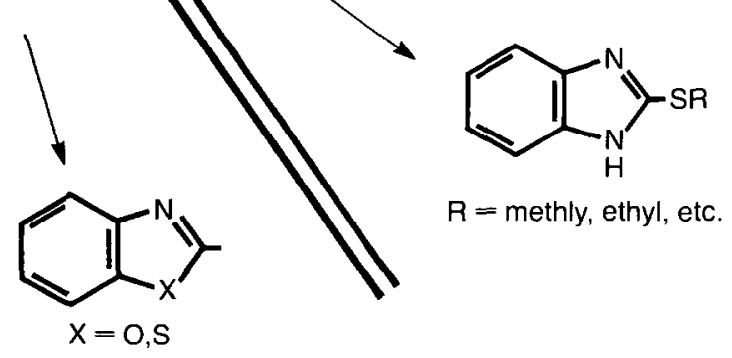

$R=$ methly, ethyl, etc.

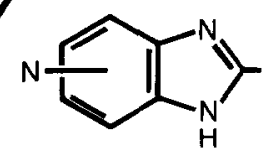

$$
x=0,5
$$


Table I. Reagents used for the formation of methyl benzimidazole carbamates

\begin{tabular}{|c|c|c|}
\hline Structure & Name & Refs \\
\hline$=\mathrm{N} \cdot \mathrm{CO}_{2} \mathrm{CH}_{3}$ & $\begin{array}{l}\text { I-methoxycarbonyl-S- } \\
\text { methylisothiourea }\end{array}$ & 10,16 \\
\hline $\mathrm{N} \cdot \mathrm{CO}_{2} \mathrm{CH}_{3}$ & $\begin{array}{l}\text { I,3-bis-(methoxycarbonyl)-S- } 10 \\
\text { methylisothiourea }\end{array}$ & $0,16,17,18$ \\
\hline $\mathrm{N}-\mathrm{CO}_{2} \mathrm{CH}_{3}$ & $\begin{array}{l}\text { methyl bis-alkyl or bis- } \\
\text { arylthiomethyleneamino } \\
\text { carboxylate }\end{array}$ & 16,19 \\
\hline $\mathrm{NC}-\mathrm{NH}-\mathrm{CO}_{2} \mathrm{CH}_{3}$ & carbomethoxycyanamide & 16,20 \\
\hline $\mathrm{Cl}^{\prime} \mathrm{C}=\mathrm{N}-\mathrm{CO}_{2} \mathrm{CH}_{3}$ & $\begin{array}{l}\text { methyl bis-(chloro)methylene- } \\
\text { amino carboxylate }\end{array}$ & 21 \\
\hline $\mathrm{S}=\mathrm{C}=\mathrm{N} \cdot \mathrm{CO}_{2} \mathrm{CH}_{3}$ & methoxycarbonyl isothiocyanate & 15,22 \\
\hline
\end{tabular}
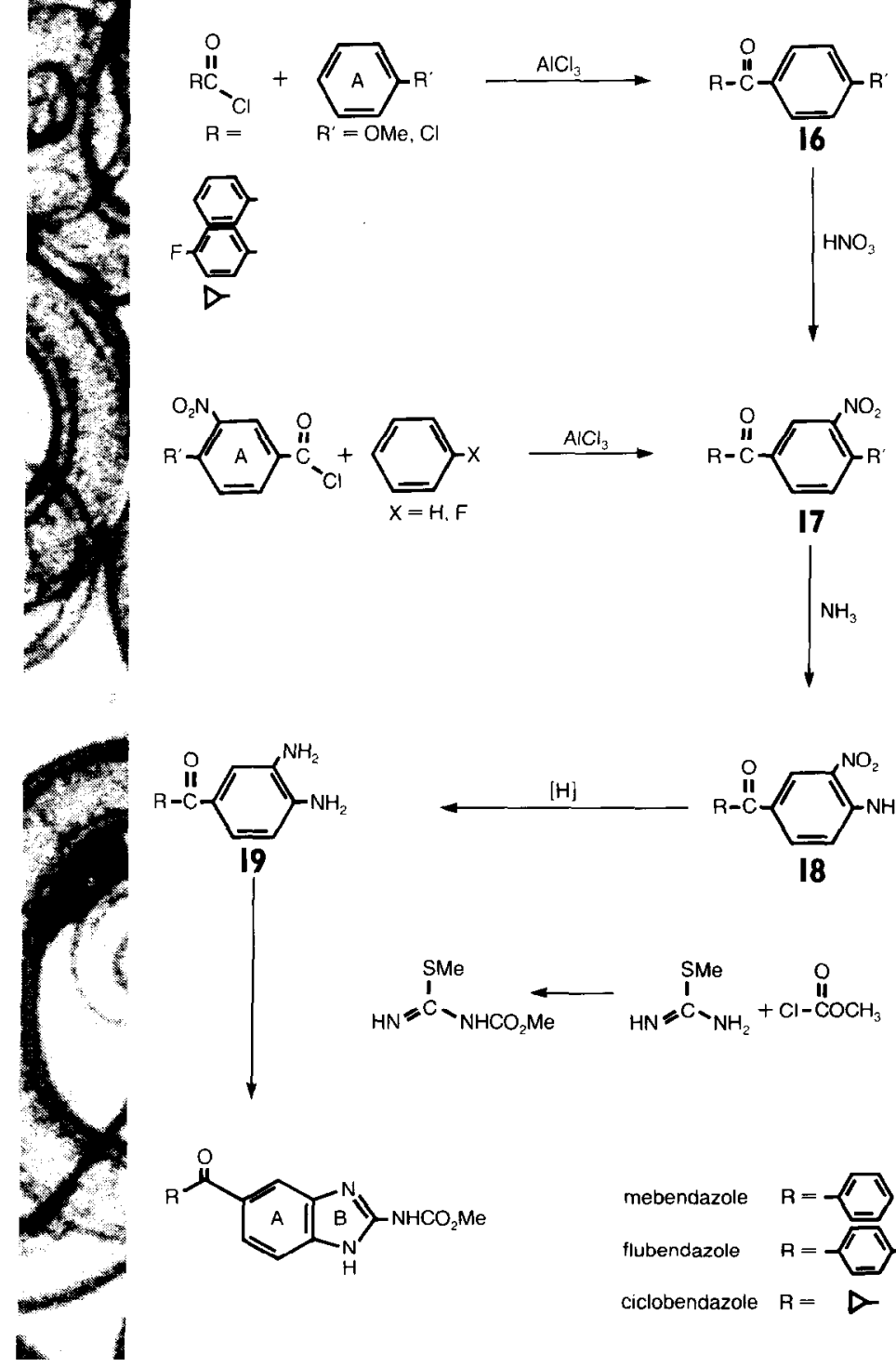

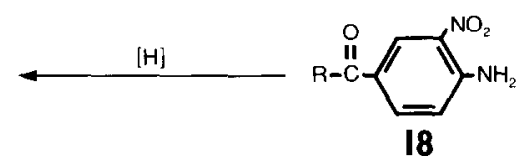

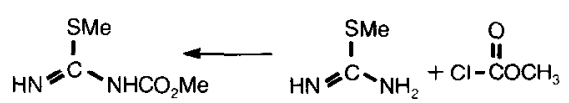<smiles>CC(=O)Nc1nc2cc(C(C)=O)ccc2[nH]1</smiles>

mebendazole

flubendazole

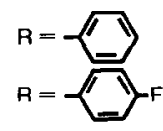

ciclobendazole $R=D$ classical Friedel-Craft acylation with either an aromatic or aliphatic acid chloride and methoxy-or chlorobenzene to give (16). Compound (16) is then converted to (17) by nitration at the site adjacent to the methoxyl- or chloro- group. Alternatively, the 3-nitro-4-chloro derivative (I7) could be made in one step by acylation of 3-nitro-4-chlorobenzoyl chloride. Owing to the electron donating effects of the adjacent nitro group, the 4-methoxy or chloro group is readily comverled to the 3-nitro-4-aniline derivative (18). Reduction of the nitro group by a variety of methods gives (19), which is ring closed to the desired benzimidazole using methoxycarbonyl-Smethylisothiourea.

To prepare oxfendazole ${ }^{14}$ the necessary diamine $(\mathbf{2 4})$ is prepared by a series of reactions including a nucleophilic
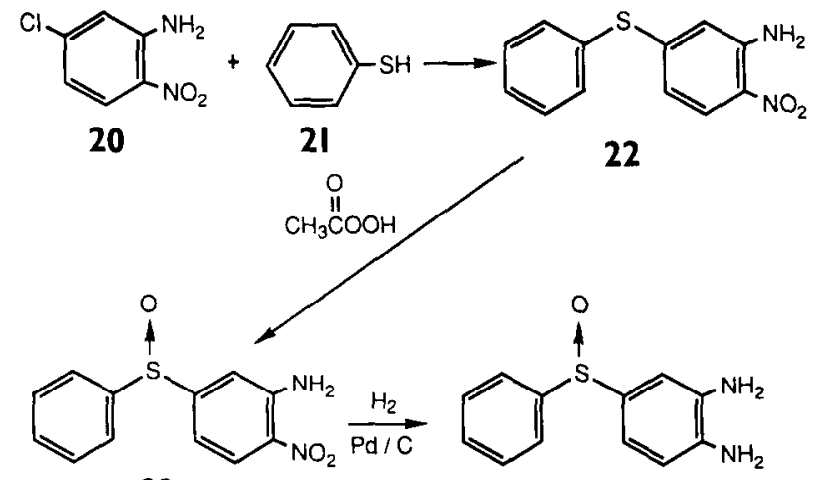

23

24<smiles>COCCOc1ccc2[nH]c(NC(C)=O)nc2c1</smiles>

substitution of the chloro moiety of 2-amino-4chloronitrobenzene (20) with thiophenol $(\mathbf{2 I})$ in the presence of potassium carbonate. This reaction affords 2-amino-4phenylsulfurylnitrobenzene (22). Oxidation of (22) with one equivalent of peracetic acid gives the sulfoxide (23), which is selectively hydrogenated to give (24). Oxfendazole is obtained by an annulation of the diamine system of (24) with 1,3-bis(methoxycarbonyl)-S-methylisothiourea.

The synthetic steps required to prepare albendazole 'l further illustrate how the benzene ring may be modified before ring closure to the benzimidazole system. In this five step synthesis, 4-chloro-2-nitroaniline (25) is first acetylated with acetic anhydride to give 1 -acetamido-4-chloro-2-nitrobenzene (26). Treatment of (26) with potassium thiocyanate furnishes the key intermediate 1-acetamido-2-nitro-4thiocyanatobenzene (27). Conversion of the thiocyanato group of (27) into the required n-propylthio- analog, with a simultaneous conversion of the acetamido group to the free amine, is effected by treating (27) with I-bromopropane in the presence of a base. Reduction of the nitro group of $(\mathbf{2 8})$ provides the diamine (29), which is subsequently ring closed to albendazole.

In an alternative synthesis, mebendazole has also been reported ${ }^{15}$ to be prepared in good yield from benzo-2, 1,4thiadiazines. 2-Amino-4-benzoyl-nitrobenzene (30) was con- 


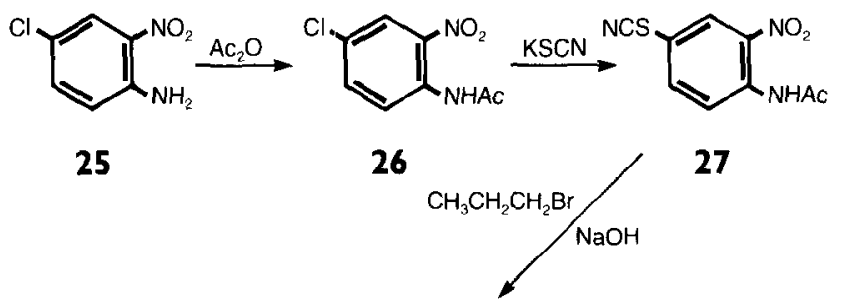<smiles>CCCSc1ccc(N)c([N+](=O)[O-])c1</smiles><smiles>CCCSc1ccc2[nH]c(NC(C)=O)nc2c1</smiles>

albendazole

densed with methoxycarbonyl isothiocyanate to give an $o$-nitroarylthiocarbamoylcarbamate (3I). Reduction with sodium dithionite gives the key intermediate benzo-2, 1,4-thiadiazine (32). Reaction of (32) with triphenylphosphine gives a yield of $99 \%$.<smiles>COC(=O)NC(=S)Nc1cc(C(=O)c2ccccc2)ccc1N(C)OC(=O)[O-]</smiles>
30 31

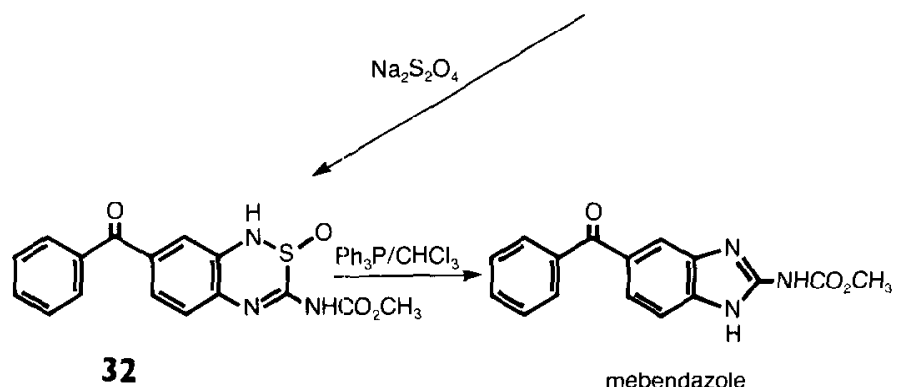

Both mebendazole and flubendazole have been prepared in an improved overall yield by a series of reactions shown below. In this synthesis ${ }^{22}$, the key step is a ring closure of the appropriate diamine with methoxycarbonyl isothiocyanate, in the presence of dicyclohexyl carbodiimide (DDC) in acetonitrile. The overall yields are $77 \%$ of mebendazole and $55 \%$ of flubendazole, respectively.

Poor drug absorption and lack of water solubility are problems that limit the use of most benzimidazole carbamates against intestinal parasites. In addition, recently developed resistance to the current commercially available drugs by certain parasites is also of concern, and together these problems have prompted the development of new benzimidazole carbamatc typcs. Among these are heterocyclic isosteres, compounds which contain a heterocyclic core other than benzimidazole. Prodrugs are being developed that are appropriately substituted benzene molecules that are enzymatically converted to an active benzimidazole carbamate after absorption by the animal under treatment.

A series of 6-substituted imidazo[1,2-a]pyridine-2carbarnates have been prepare ${ }^{23}$, and one of these (40) has shown higher activity than any known benzimidazole against

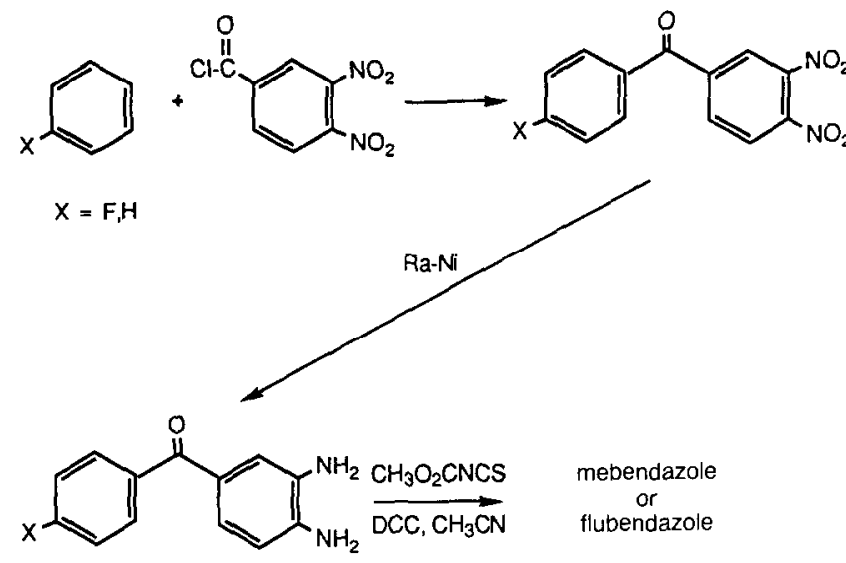

certain parasites. To synthesize (40), the picoline (34) is prepared by the addition of chlorine to 5-ethynyl-2-methylpyridine (33) and is subsequently dehydrohalogenated with a strong base to furnish the 5-trichloro substituted intermediate (35). Four more synthetic steps (35-39) are necessary in order to convert the 2-methyl group of $(\mathbf{3 5})$ to the 2 -amino derivative (39). Ring cyclization of (39) with methyl (chloroacetyl) carbamate produced the target compound $(\mathbf{4 0})$. This compound is still under investigation.<smiles>C#Cc1ccc(C(Cl)=C(Cl)c2ccc(C(=O)O)nc2)cc1</smiles><smiles>CC(=O)Nc1cn2cc(C(Cl)(Cl)C(C)=O)ccc2n1</smiles>

Examples of prodrugs are thiophanate (methyl) $(\mathbf{4 1})^{24}$ febantcl $(\mathbf{4 2})^{25}$ and netobimin $(\mathbf{4 3})^{26}$; all of which are converted to benzimidazole carbamates by the host. For example

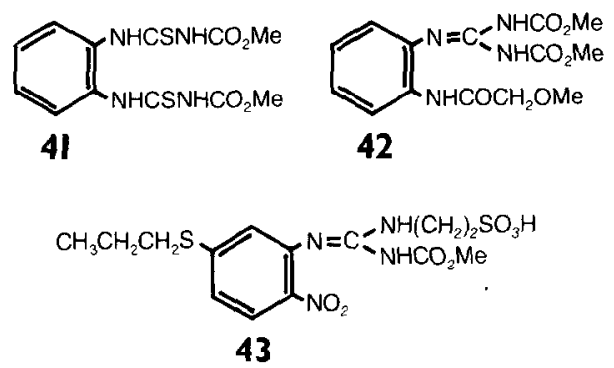

netobimin (43) has been shown to undergo a reduction of the nitro group by microflora of the intestine ${ }^{27}$. The resulting ortho amino derivative cyclizes to methyl 5-(propylthio)benzimidazole carbamate (44). The synthesis of netobimin was<smiles>CCCSC1=CC(N=C(NCCS(=O)O)NC(C)=O)=C(N)c2cc(SCCC)ccc2N1</smiles> 
<smiles>CCCSc1ccc([N+](=O)[O-])c(N=C(NC(C)=O)C(=O)O)c1</smiles>

\section{5}

accomplished by trcatment of the 5-methylisothiourea derivative (45) with taurine. It should be noted that netobimin as a salt is freely soluble in water and, as such, has major advantages over the benzimidazoles per se. This is an area of research that has great promise.

We have attempted to show a few examples of benzimidazole syntheses that have shown great value to humankind. Does the synthesis of new benzimidazoles still have merit, and is research in this area still going on? The answer is yes. Resistance to the now commercially available benzimidazoles has developed and poor oral absorption remain problems which have yet to be solved.

\section{Acknowledgement}

This study was supported by the filariasis component of the World Bank/UNDP/WHO Special Program for Research and Training in Tropical Diseases (I.D. 870387)

\section{References}

1 Tuwnsend, L.B. and Revankar, G.R. (1970) Chem. Rev. 70, 389-438

2 Preston, P.N. (1981) Benzimidazoles and Congeneric Tricyclic Compounds Part 1 and Part 2 John Wiley and Sons

3 Grimmett, M.R. (1984) in Comprehensive Heterocyclic Chemistry (Katritzky, A.R. and Rees, C.W., eds), (Vol. 5) pp 345-498, Pergamon Press 4 Brown, H.D. et al. (1961)J. Am. Chem. Soc. 83, 1764-1765
5 Grenda, V.J., Jones, R.E., Gal, G. and Sletzinger, (1965) J. Org. Chem. 30 , 259-261

6 Hoff. D.R. etal. (1970) Experientia 26. 550

7 Ellsworth, R.L., Hinkley, D.F. and Schoenewaldt, E.F. (1971) Chem. Abstr. $74,76424 \mathrm{q}$ (French Patent 2014308)

8 Ellsworth, R.L., Hinckley, D.F. and Schoenewaldt, E.F. (1971) Chem. Abstr. $74,76423 \mathrm{p}$ (French Patent 2014422)

9 Actor, P. et al. ( I 967) Nature 215, 321-322

10 Raeymaekers, A.H.M., Van Gelder, J.L.H., Roevens, L.F.C. and Janssen, P.A.J.(1978) Arzneim.-Forsch. Drug Res. 28, 587-594

II Theodorides, V..., Gyurik, R..., Kingsbury, W.D. and Parish, R.C. (1976) Experientia 32,702

12 Theodorides, V.J.et al (1973)Br. Vet.J. 129, vovii

13 Baeder, C. et al. (1974) Experientia 30,753

14 Averkin, E.A. et al.(1975) J.Med. Chem. 18, 1164-1166

I5 Barker, A.C. and Foster, R.G. (1973) Chem. Abstr. 79, 534/c; $25669 \mathrm{k}$ (German Patent 2246 605)

16 Loewe, H., Kirsch, R., Urbanietz, J. and Duewel, D. (1975) Chem. Abstr. 82, | 563 | If(German Patent 2332398 )

17 Klonning, H.K. (1975) Chem. Abstr. 84, 4948x (US Patent 3896230 )

18 Olin, J.F. and Dains, F.B.(1930)J. Am. Chem. Soc. 52, 3322-3326

19 E.I. du Pont de Nemours and Co. (197I) US Patent 3562290

20 Actor, P. and Pagano, J.F. (I 975) Chem. Abstr. 84, 4950s (US Patent 28 403)

21 Widdig A. and Kuehle, E. (1971) Chem. Abstr. 74, 7864256e (German Patent ( 932 297)

22 Ram, S., Wise, L.S. and lownsend, L.B. (1985) OPPI Briefs 17, 215-218

23 Bochis, R.J. et al. (1981) J. Med. Chem. 24, 1518-1521

24 Wollweber, $H$. et al. (1978)Arzneimittelforsch 28, 2193-2195

25 Eichler, D.A.(1973) Br. Vet.). 129,533-543

26 Vashi, D.B., Clark, J.N. and Lindo, N.A. (1983) US Patent 4406893

27 Delatour, P., Cure, M.C.., Benoit, E. and Garnier, F. (1986)/. Vet. Phormacol. Ther. 9,230-234

Leroy Townsend and Dean Wise are at the Dcpartment of Mcdicinal Chemistry, College of Pharmacy and Department of Chemistry. University of Michigan, Ann Arbor, M148109, USA

\title{
Mode of Action of Benzimidazoles
}

\author{
E. Lacey
}

Benzimidazoles represent the only class of truly broad-spectrum anthelmintics, however, they also show activity against fungi and mammalian cells. This raises the question as to why benzimidazoles can selectively kill helminths and yet exhibit little or no mammalian toxicity. In this poper, Ernest Lacey examines this example of selectivity of drug action to the ubiquitous target of these drugs, the structural protein, tubulin.

With the discovery of thiabendazole in 1961, the general pattern of benzimidazoles (BZs) as a class of low-dose broadspectrum anthelmintics with a high therapeutic index was established'. The subsequent cascade of patents during the next 25 years led to the experimental or commercial development of a further $15 \mathrm{BZs}$ (see pp 107-1 12, this issue) and $B Z$ prodrugs. Central to the success of $B Z s$ is their selective toxicity for helminths. Since the mid- 1960 s the mode of action of BZs has been extensively investigated and our understanding of how $B Z s$ act has undergone radical reapprai$\mathrm{sa}^{2-4}$. In a recent review, Lacey ${ }^{4}$ con- cluded that despite the diverse effects of $\mathrm{BZs}$ at the biochemical and cellular levels, the primary mode of action of these drugs involves their interaction with the eukaryotic cytoskeletal protein, tubulin. This paper examines the paradox of the interaction of $\mathrm{BZ}$ s with a ubiquitous protein and the evidence for their selective toxicity for helminths.

\section{Tubulin and Microtubules}

The microtubule subunit, tubulin, is a dimeric protein comprised of $\boldsymbol{\alpha}$ - and $\beta$-subunits of approximately $50 \mathrm{kDa}$ each $^{5}$. Structurally, both $\alpha$ - and $\beta$-tubulins are heterogeneous proteins, products of multi-gene families as well as post-translational modifications. The sequences of tubulins from a wide diversity of species have been reported, and show a high degree of homology 5 .

Microtubules exist in dynamic equilibrium with tubulin, the ratio of dimeric tubulin to polymeric microtubules being controlled by a range of endogenous regulatory proteins and co-factors (Fig. I) ${ }^{4}$.
This equilibrium can be altered, both in vivo and in vitro, by exogenous substances known as microtubule inhibitors. Most, but not all, such inhibitors exert their action by binding to tubulin to prevent the self-association of subunits onto the growing microtubules. This results in a 'capping' of the microtubule at the associating end while the microtubule continues to dissociate from the opposing end, with a net loss of microtubule length. One implication of this phenomenon is that it is not necessary for inhibitors to bind all tubulin dimers to inhibit polymerization, it is sufficient for them simply to 'cap' the microtubule.

Microtubule inhibitors are a group of structurally diverse compounds produced by fungi, plants, marine organisms, possibly higher eukaryotic animals and, more recently, synthetically. They show a wide spectrum of selective and nonselective toxicity against eukaryotic genera. Some of the well-characterized microtubule inhibitors, such as vinblastine and vincristine, have found a use in cancer chemotherapy, but most are too toxic for therapeutic use. 